\title{
Gastric Cancer pNO TNM Finding v8
}

National Cancer Institute

\section{Source}

National Cancer Institute. Gastric Cancer pNO TNM Finding v8. NCI Thesaurus. Code C133619.

Gastric cancer with no metastasis to regional lymph nodes. (from AJCC 8th Ed.) 